\title{
PAPER
}

\section{Bladder dysfunction in acute transverse myelitis: magnetic resonance imaging and neurophysiological and urodynamic correlations}

\author{
J Kalita, S Shah, R Kapoor, U K Misra
}

J Neurol Neurosurg Psychiatry 2002;73:154-159

See end of article for authors' affiliations

.....................

Correspondence to: Professor U K Misra, Department of Neurology, Sanjay Gandhi

Postgraduate Institute of Medical Sciences,

Raebareily Road, Lucknow 226023, India;

ukmisra@sgpgi.ac.in

Received 13 August 2001 In revised form 27 March 2002

Accepted 3 April 2002

\begin{abstract}
Aims: To evaluate micturition abnormalities in acute transverse myelitis and correlate these with evoked potentials, magnetic resonance imaging (MRI), and urodynamic findings.

Setting: Tertiary care teaching hospital.

Patients: 18 patients with acute transverse myelitis, aged $4-50$ years; 15 had paraparesis and three quadriparesis.

Methods: Patients with acute transverse myelitis had a neurological evaluation and tibial somatosensory and motor evoked potential studies in the lower limbs. Spinal MRI was carried out using a $1.5 \mathrm{~T}$ scanner. Urodynamic studies were done using Dantec UD 5500 equipment. Neurological outcome was determined on the basis of Barthel index score at six months as poor, partial, or complete. In some patients, urodynamic studies were repeated at six and 12 months.

Results: Spinal MRI in 14 of the 18 patients revealed T2 hyperintense signal changes extending for at least three spinal segments in 13; one patient had normal MRI. In the acute stage, 17 patients had a history of urinary retention and one had urge incontinence. On follow up at six months two patients regained normal voiding, retention persisted in six, and storage symptoms developed in 10, of whom five also had emptying difficulties. Urodynamic studies showed an areflexic or hypocontractile bladder in 10, detrusor hyperreflexia with poor compliance in two, and detrusor sphincter dyssynergia in three. Early abnormal urodynamic findings commonly persisted at the six and 12 months examinations. Persistent abnormalities included detrusor hyperreflexia, dyssynergia, and areflexic bladder. The urodynamic abnormalities correlated with muscle tone and reflex changes but not with sensory or motor evoked potentials, muscle power, MRI signal changes, sensory level, or six months outcome.

Conclusions: Bladder dysfunction is common in acute transverse myelitis and may be the only sequel. Urodynamic study is helpful in evaluating the bladder dysfunction and also in its management.
\end{abstract}

Bladder dysfunction caused by spinal cord lesions has been evaluated in multiple sclerosis, spinal cord injury, myelodysplasia, and craniovertebral junctional anomaly. ${ }^{1-3}$ In acute transverse myelitis, bladder dysfunction is an integral component of the diagnosis and may be one of the most disabling sequelae in spite of near total recovery of other neurological deficits. ${ }^{4}$ Recent developments in neurophysiology, imaging, and urodynamic evaluation have provided a unique opportunity to evaluate bladder function in patients with acute transverse myelitis, as there have been very few studies examining bladder function in such patients. ${ }^{45}$ Those studies were limited by small numbers, lack of clinicoradiological correlation, and inadequate follow up. Our aim in the present study was to evaluate bladder function in patients with acute transverse myelitis and correlate it with clinical findings and with magnetic resonance imaging (MRI) and evoked potential changes.

\section{METHODS}

Patients with acute transverse myelitis seen during 1998 to 2000 were included in the study. The diagnosis was based on the following criteria ${ }^{6}$ :

- Acutely or subacutely developing motor, sensory, and sphincter disturbance;

- Spinal segmental level of sensory disturbance with a well defined upper limit;

- No clinical or laboratory evidence of spinal cord compression;
- Absence of other known neurological disease such as syphilis, previously diagnosed multiple sclerosis, malignant neoplasm, spinal cord arteriovenous malformation, sarcoidosis, or HIV infection;

- Lack of clinical progression after four weeks.

All the patients underwent a detailed neurological examination. Weakness was assessed on the Medical Research Council (MRC) scale (0-5) and spasticity by the Ashworth scale. ${ }^{7}$ Tendon reflexes, plantar responses, and sensation were recorded.

The following laboratory tests were done in all patients: haemoglobin, blood count, erythrocyte sedimentation rate, serum chemistry, serum syphilis testing, HIV testing, rheumatoid factor, and antinuclear antibodies. Cerebrospinal fluid was examined for protein, sugar, cells, bacteria, and fungi.

Spinal MRI was carried out on a 2T superconducting system operating at $1.5 \mathrm{~T}$, using a flat oval surface coil. All the images were obtained using multislice spin echo sequences which included gradient motion rephasing to reduce motion induced artefacts. Tl weighted images $(500 / 15 / 3=\mathrm{TR}$ in $\mathrm{ms} / \mathrm{TE}$ in ms/excitations), proton density images (2200-2500/15-20/1), and T2 weighted images (2200-2500/80-90/1) were obtained in the sagittal and axial plains.

\section{Evaluation of bladder function}

A history of bladder involvement (retention, frequency, hesitancy, urgency, straining, and urge incontinence) was obtained, and inquiries were made about constipation, stool incontinence, and erectile dysfunction. Sweating, lack of 
Table 1 Clinical, radiological, and urodynamic findings in patients with acute transverse myelitis in the acute stage

\begin{tabular}{|c|c|c|c|c|c|c|c|}
\hline Case No & Age/sex & $\begin{array}{l}\text { Bladder } \\
\text { symptoms }\end{array}$ & Tone & LL power & $\begin{array}{l}\text { MRI vertebral } \\
\text { level }\end{array}$ & $\begin{array}{l}\text { Urodynamic } \\
\text { study }\end{array}$ & $\begin{array}{l}6 \text { months } \\
\text { outcome }\end{array}$ \\
\hline 1 & $45 / M$ & $R$ & $\downarrow$ & 0 & D11 & DA & Poor \\
\hline 2 & $24 / M$ & $R$ & $\downarrow$ & 0 & D1 2 to $\mathrm{L} 1$ & DA & Complete \\
\hline 3 & $11 / F$ & $R^{*}$ & $\downarrow$ & 0 & $\mathrm{C} 2$ to $\mathrm{C} 6$ & DA & Complete \\
\hline 4 & $22 / M$ & $\mathrm{R}$ & $\downarrow$ & 0 & D6 to D10 & DA & Complete \\
\hline 5 & $26 / M$ & Fr, U, Ul & $\uparrow$ & 2 & D6 to D 10 & $\mathrm{DH}$ & Complete \\
\hline 6 & $27 / M$ & $\mathrm{R}^{*}$ & $\downarrow$ & 0 & ND & DSD & Complete \\
\hline 7 & $13 / M$ & $\mathrm{R}$ & $N$ & 2 & D3 to D6 & DSD & Complete \\
\hline 8 & $13 / F$ & $\mathrm{R}^{*}$ & $\downarrow$ & 0 & ND & DSD & Poor \\
\hline 9 & $40 / M$ & $\mathrm{R}$ & $\downarrow$ & 0 & ND & DA & Poor \\
\hline 10 & $21 / M$ & $R$ & $\downarrow$ & 0 & $\mathrm{C} 5$ to $\mathrm{C} 7$ & DA & Complete \\
\hline 11 & $15 / M$ & $R$ & $\downarrow$ & 0 & C6 to D6 & DA & Poor \\
\hline 12 & $23 / M$ & $R$ & $\uparrow$ & 4 & D3 to $L 2$ & DA & Complete \\
\hline 13 & $4 / M$ & $R$ & $\uparrow$ & 0 & D1 to D10 & $\mathrm{DH}$ & Partial \\
\hline 14 & $11 / \mathrm{M}$ & $\mathrm{R}^{*}$ & $\downarrow$ & 3 & $\mathrm{D} 1$ to $\mathrm{L} 1$ & DA & Complete \\
\hline 15 & $25 / F$ & $\mathrm{R}$ & $\downarrow$ & 0 & D1 2 to $L 1$ & DA & Poor \\
\hline 16 & $45 / F$ & $R$ & $\downarrow$ & 0 & $C 7$ to $D 3$ & ND & Complete \\
\hline 17 & $50 / \mathrm{F}$ & $R$ & $\downarrow$ & 0 & Normal & ND & Poor \\
\hline 18 & $28 / M$ & $R$ & $\downarrow$ & 0 & ND & ND & Complete \\
\hline
\end{tabular}

sweating, and syncopal attacks were documented. Perianal sensation, cremasteric reflex, and anal tone were recorded.

\section{Neurophysiological studies}

Neurophysiological studies included recordings of motor evoked potentials to the lower limbs, tibial somatosensory evoked potential, and concentric needle electromyography (EMG) of the lower limb muscles. Motor evoked potentials were recorded from the lower limbs bilaterally following transcranial electrical stimulation of the cerebral cortex and spine. A Digitimer D180 stimulator (Digitmer Ltd, Welwyn, Herts, UK) delivering electrical shocks at up to $750 \mathrm{~V}$ with a time constant of 50-100 $\mu$ s was used. The stimulating electrode was a $1 \mathrm{~cm}$ diameter saline soaked felt pad mounted on a plastic handle. For activating the tibialis anterior muscle, the anode was kept at the vertex and the cathode $7 \mathrm{~cm}$ posterior. For lumbar stimulation, the cathode was placed below the spinous process of the 12th dorsal vertebra and the anode proximal to it.

Motor evoked potentials were recorded by a surface electrode from the tibialis anterior in a belly tendon montage. During cortical stimulation, the patient was asked to contract the target muscles slightly ( $10 \%$ of maximum force), while during the spinal stimulation the patient was asked to relax. Electromyographic signals were filtered through $20 \mathrm{~Hz}$ to 2 $\mathrm{kHz}$ at a gain of 0.5-1.0 mV/division. The stimulus intensity was $90-100 \%$ of maximum output for cortical stimulation and $60-70 \%$ for spinal stimulation. Three responses were obtained and the potential with the shortest latency was used for the analysis. Central motor conduction time to tibialis anterior (CMCT-TA) was calculated by subtracting the Ll latency from $\mathrm{Cz}$.

Tibial sensory evoked potentials were investigated by stimulating the posterior tibial nerve below the medial malleolus, employing a $0.1 \mathrm{~ms}$ square wave pulse at $3 \mathrm{~Hz}$, sufficient to produce a painless twitch of the big toe. The recording electrode was placed at the spinous process of the first lumbar vertebra and $2 \mathrm{~cm}$ caudal to $\mathrm{Cz}$. The reference electrodes were placed at L3 and Fz, respectively. The electrode impedance was kept below $5 \mathrm{k} \Omega$, with a frequency band pass of $2-3000 \mathrm{~Hz}$ and an analysis time of $100 \mathrm{~ms}$. We averaged 512 responses twice at a gain of $1-2 \mu \mathrm{V} /$ division to ensure reproducibility. The latencies of N21, P40, and N21-P40 central sensory conduction time (CSCT) were measured. The results of evoked potentials were compared with our laboratory's normal values which were obtained from 32 healthy adult volunteers. ${ }^{8}$ Abnormality was defined as mean $+2.5 \mathrm{SD}$ of control values. On this basis, the upper limit of CMCT-TA is $16.1 \mathrm{~ms}$, and of tibial CSCT, $27.1 \mathrm{~ms}$.

\section{Urodynamic studies}

Urodynamic studies were carried out using Dantec UD 5500 equipment (Dantec Inc, Copenhagen, Denmark). A double lumen 6-8 F urethral catheter was introduced and normal saline was instilled at a rate of $5-20 \mathrm{ml} / \mathrm{min}$ to fill the bladder. Vesical, abdominal, and detrusor pressures were monitored simultaneously during the filling and voiding phases. Bladder volume at the first sensation, maximum bladder capacity, bladder compliance, filling pressure, opening pressure, and detrusor pressure at maximum flow were recorded. Maximum and average flow rates, as well as post-voiding residual urine volume, were also recorded. Surface electromyography of the external sphincter was done to study sphincter activity. The mean (SD) normal value for first sensation of filling is 252.9 (124) $\mathrm{ml}$ in male subjects and 153.5 (91.6) $\mathrm{ml}$ in female subjects, ${ }^{9}$ and bladder capacity ranges between $400 \mathrm{ml}$ and 750 $\mathrm{ml} .{ }^{10}$ The end filling pressure was considered normal if it was less than $20 \mathrm{~cm} \mathrm{H}_{2} \mathrm{O}$ at full bladder capacity. ${ }^{4}$

On the basis of the urodynamic studies, bladder dysfunction was classified into three groups:

(1) Detrusor areflexia, defined as acontractility caused by abnormality of nervous control, and detrusor hyporeflexia, defined as detrusor contraction of inadequate magnitude and/or duration to effect bladder emptying in a normal time span. Patients with detrusor areflexia and detrusor hyporeflexia were grouped together in subsequent analyses because of the small sample size and similar management;

(2) Detrusor external sphincter dyssynergia, defined as detrusor contraction concurrent with a involuntary contraction of the urethral and/or periurethral striated muscle;

(3) Detrusor hyperreflexia, defined as involuntary detrusor contraction during the filling phase which may be spontaneous or provoked, and cannot be completely suppressed owing to disturbance of nervous control mechanisms. ${ }^{11}$

Patients with detrusor areflexia or hyporeflexia were managed with clean intermittent catheterisation. For detrusor hyperreflexia, oxybutynin was prescribed. Detrusor sphincter 


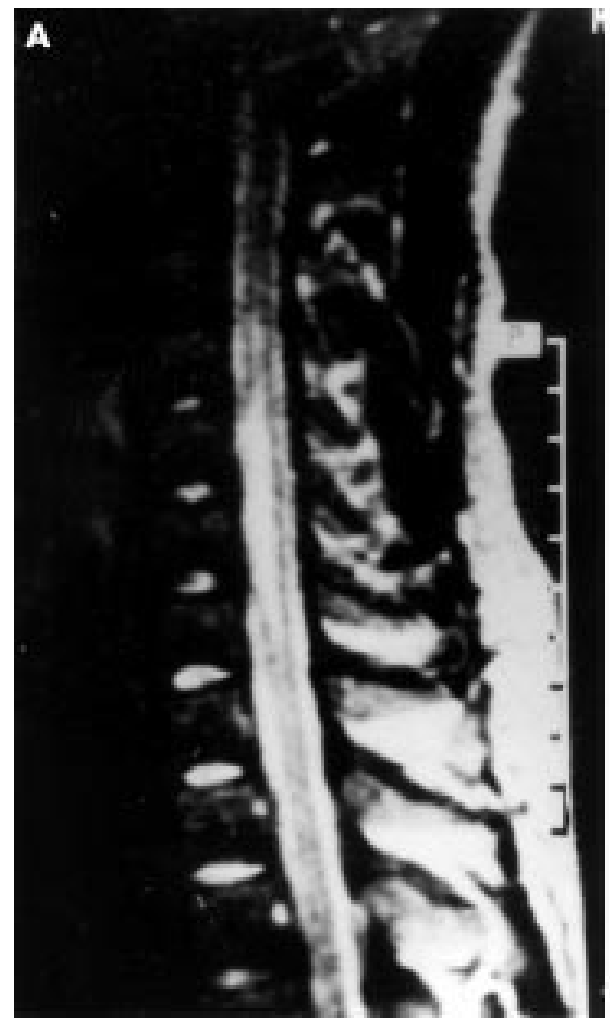

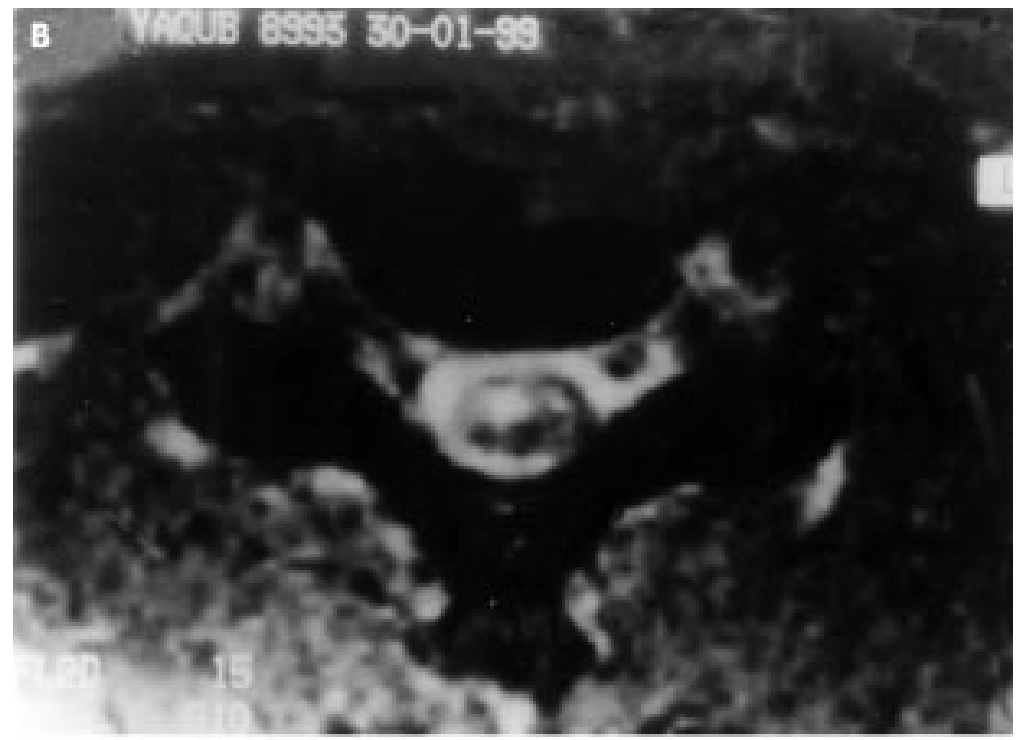

Figure 1 Spinal magnetic resonance imaging: T2 sequence showing hyperintense signal changes in the cervicodorsal region in sagittal section (panel A), mostly involving the central part of spinal cord, shown in axial section in panel B. dyssynergia was managed with clean intermittent catheterisation and anticholinergics.

In some patients with acute transverse myelitis, the clinical and urodynamic studies were repeated at six months and one year. The outcome was defined at the end of six months on the basis of the Barthel index score $(\mathrm{BI})^{12}$ as poor $(\mathrm{BI}<12)$, partial $(B I=12-19)$, and complete $(B I=20)$. For statistical analysis, bladder dysfunction was grouped into detrusor hyporeflexia or areflexia, detrusor hypereflexia, and detrusor sphincter dyssynergia.

Loss of lower limb power was graded as severe (MRC grade $0-1)$, moderate (MRC grade II-III), or mild (MRC grade IV or V). Muscle tone was classified as hypotonic, normal, or spastic; reflex changes as reduced, normal, or increased; and sensory level as cervical, thoracic, or lumbar. MRI changes were graded according to whether they extended for less than or more than six spinal segments. The predominant location of the MRI changes was classified as cervicodorsal or lumbar, and the changes in motor and somatosensory evoked potentials as normal, prolonged, or unrecordable.

The relations between clinical, urodynamic, and MRI findings were evaluated by the $\chi^{2}$ test.

\section{RESULTS}

We studied 18 patients with acute transverse myelitis, their ages ranging between 4 and 50 years (mean 24.6). A history of preceding fever was present in six patients, 15 had paraparesis, and three had quadriparesis.

The clinical, MRI, and initial urodynamic findings are presented in table 1 . Knee and ankle reflexes were brisk in four, reduced in 12, and normal in two, and the plantar responses were extensor in eight. The lower limbs were wasted in five patients. Segmental sensory loss was in the dorsal region in 14, in the cervical region in one, and in the lumbar region in three. Posterior column sensation was impaired in the lower limbs in all the patients. The upper limbs were weak and hyperreflexic in three patients.

\section{MRI}

Spinal MRI was carried out in 14 patients and was abnormal in all except one. Computed tomographic myelography was carried out in three patients and a conventional myelogram in one; these were all normal. MRI was carried out in the acute stage and revealed $\mathrm{T} 2$ hyperintense signal changes extending for at least three spinal segments (mean number of segments 8.5, range 3 to 22). The signal changes were present in the central two thirds of the spinal cord in most patients. The signal changes were mainly in dorsal spinal segments in eight patients (Nos 4, 5, 7, 11, 12, 13, 14, and 16), in cervical segments in two (Nos 3 and 10), and in lumbosacral segments in three (Nos 1, 2, and 15) (fig 1). Two patients had marked signal changes extending from dorsal to lumbosacral spinal segments (Nos 12 and 14). One patient had Tl hyperintensity suggestive of haemorrhage.

\section{Bladder symptoms and urodynamic studies}

Of 18 patients evaluated in the acute stage, 17 had a history of urinary retention for which they were catheterised. However, four of these patients were able to void partially during the urodynamic study. The details of the clinical and urodynamic findings are given in table 1 , and examples of the urodynamic findings in fig 2. In 10 patients with areflexic or hyporeflexic bladders, the sensation of filling was absent in five, while in the remaining five bladder sensation was noted at $91-505 \mathrm{ml}$ (mean 197.2). Bladder compliance was reduced in three patients and normal in one. Bladder capacity in this group ranged between 230 and $700 \mathrm{ml}$ (mean $400.4 \mathrm{ml}$ ). In two patients with detrusor hyperreflexia, bladder sensation was absent, compliance was poor, and bladder capacity was $78 \mathrm{ml}$ in one and $194 \mathrm{ml}$ in the other. Detrusor pressure was raised to 71 and $21 \mathrm{~cm} \mathrm{H}_{2} \mathrm{O}$. In three patients with detrusor sphincter dyssynergia, bladder sensation was noted at 61, 177, and 200 $\mathrm{ml}$. Bladder compliance was poor in one, bladder capacity was between 250 and $340 \mathrm{ml}$, and the detrusor pressure was between 30 and $60 \mathrm{~cm} \mathrm{H}_{2} \mathrm{O}$. Two patients with a hyporeflexic bladder and two with detrusor sphincter dyssynergia were 

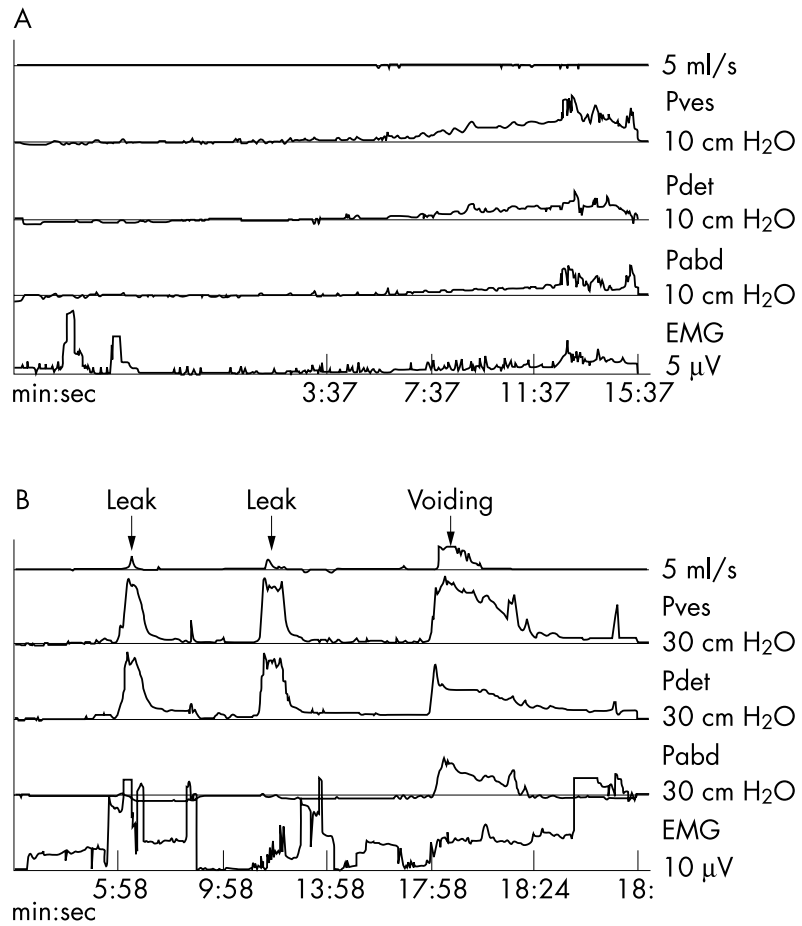

Figure 2 (A) Urodynamic study of patient No 3 in the acute stage of acute transverse myelitis, showing detrusor hyporeflexia with maximum vesical pressure (Pves) of $20 \mathrm{~cm} \mathrm{H}_{2} \mathrm{O}$ and maximum detrusor pressure (Pdet) of $12 \mathrm{~cm} \mathrm{H}_{2} \mathrm{O}$ with voiding. (B) Urodynamic study of the same patient six months later, revealing detrusor sphincter dyssynergia (repeated detrusor contraction with leakage of urine during the filling phase and sphincter contraction during the voiding phase). Maximum Pves, $105 \mathrm{~cm} \mathrm{H}_{2} \mathrm{O}$; maximum Pdet, 105 $\mathrm{cm} \mathrm{H} \mathrm{H}_{2} \mathrm{O}$. Pabd, abdominal pressure; $E M G$, sphincter electromyography.

able to void voluntarily, and residual urine was increased (to more than $150 \mathrm{ml}$ ) in two patients.

All the patients were followed up clinically for at least six months. The clinical and urodynamic findings at follow up are presented in table 2. Urodynamic studies at six months were carried out in six patients, and in five of these they were repeat studies. Differences were noted in two patients in whom detrusor areflexia was replaced by detrusor hyperreflexia with detrusor sphincter dyssynergia. In two other patients, the areflexic hypocontractile bladder persisted and in these patients the bladder capacity was $450 \mathrm{ml}$ and $644 \mathrm{ml}$, respectively. Bladder sensation was absent in one patient with an areflexic bladder, and in the remaining patients sensation appeared at between 26 and $150 \mathrm{ml}$ (mean $54.3 \mathrm{ml}$ ). Compliance was reduced in one patient, who also had detrusor sphincter dyssynergia with detrusor hyperreflexia. Four patients with detrusor hyperreflexia had a detrusor leak point pressure of between 70 and $90 \mathrm{~cm} \mathrm{H}_{2} \mathrm{O}$, the flow rate was normal in one, and a increased residual volume was noted in two.

After one year, eight patients were followed up clinically and their urinary symptoms are detailed in table 2 . Urodynamic studies were carried out in four, and in two of these they were repeat studies. The urodynamic findings changed in one patient only. In this patient detrusor sphincter dyssynergia changed to detrusor hyperreflexia. Bladder sensation was absent in one patient with detrusor areflexia, and the remaining patients had their first sensation at 78 to $100 \mathrm{ml}$. Bladder compliance was reduced in two patients and increased in one patient who had detrusor areflexia. Bladder capacity was $603 \mathrm{ml}$ in this latter patient, while three patients with detrusor hyperreflexia had a detrusor leak point pressure of between 40 and $90 \mathrm{~cm} \mathrm{H}_{2} \mathrm{O}$.
Neurophysiological findings and their correlation with urodynamic studies

Central motor conduction time to the tibialis anterior muscle (CMCT-TA) was measured in all patients. It was unrecordable in 13 (25 sides), prolonged in three (five sides), and normal in two (four sides).

Tibial sensory evoked potentials were examined 16 patients. They were unrecordable in nine (18 sides). Central sensory conduction time was prolonged in two patients (two sides) and normal in five ( 10 sides).

Needle EMG of lower limb muscles revealed $2+$ to $3+$ fibrillations in five patients and $1+$ fibrillation in two.

On initial examination, the three types of urodynamic abnormality did not show any correlation with motor evoked potentials $\left(\chi^{2}=4.95, \mathrm{df}=4, \mathrm{NS}\right)$ or with abnormalities of sensory evoked potentials $\left(\chi^{2}=3.71, \mathrm{df}=4, \mathrm{NS}\right)$. Of 10 patients with detrusor areflexia or hyporeflexia, seven had an unrecordable CMCT-TA, in one it was prolonged, and in two it was normal. Of three patients with detrusor sphincter dyssynergia, two had an unrecordable CMCT-TA and in one it was prolonged. The patient with detrusor hyperreflexia had an unrecordable CMCT-TA. Of 10 patients with detrusor areflexia, five had unrecordable tibial sensory evoked potentials and one had a prolonged tibial central sensory conduction time. Of three patients with detrusor sphincter dyssynergia, two had normal tibial sensory evoked potentials and in one they were unrecordable; the patient with detrusor hyperreflexia had unrecordable tibial sensory evoked potentials.

At six months, 11 patients had complete functional recovery, one had partial recovery, and six had poor recovery. Complications of back pressure on the upper urinary tract developed in two patients. One patient developed bladder calculus at follow up, while another had a bladder diverticulum. Clean intermittent self catheterisation was tried in all patents with retention, but only four were able to comply with this treatment.

Initial bladder dysfunction on urodynamic studies correlated with lower limb muscle tone $\left(\chi^{2}=13.36, \mathrm{df}=4\right.$, $\mathrm{p}<0.01)$ and with reflex changes $\left(\chi^{2}=15.82, \mathrm{df}=4\right.$, $\mathrm{p}<0.01)$, but not with muscle power $\left(\chi^{2}=2.39, \mathrm{df}=4, \mathrm{NS}\right)$, extent of MRI signal changes $\left(\chi^{2}=1.1, \mathrm{df}=2\right.$, NS $)$, location of MRI changes $\left(\chi^{2}=2.81, \mathrm{df}=2, \mathrm{NS}\right)$, horizontal sensory level $\left(\chi^{2}=1.39, \mathrm{df}=4, \mathrm{NS}\right)$, or six month outcome $\left(\chi^{2}=7.35\right.$, $\mathrm{df}=4, \mathrm{NS})$.

When correlating recovery from weakness with bladder dysfunction at six months, it appeared that the patients with moderate to severe weakness had persistent retention of urine. Of seven patients with severe weakness, six had retention and only one of these had frequency and urgency. All eight patients with mild weakness had frequency and urgency. Only one of the three patients with normal power had frequency and urgency. At the six month follow up the urinary symptoms were troublesome in 10 patients-because of retention in six, urge incontinence in one, nocturnal bed wetting in one, and nocturnal frequency of micturition (more than five times) in two.

\section{DISCUSSION}

All but one patient with acute transverse myelitis in our study presented with a history of retention of urine in the acute stage. On urodynamic study, however, three patterns of bladder dysfunction were noted: detrusor areflexia or hyporeflexia in $66 \%$, detrusor sphincter dyssynergia in $20 \%$, and detrusor hyperreflexia in $13.3 \%$. A Medline search produced three studies evaluating bladder function in acute transverse myelitis. In one of these, all the patients had a hypocontractile areflexic bladder; however, three of these patients did not have any sensory or motor deficit. ${ }^{13}$ In the second study, ${ }^{4}$ urodynamic investigations were carried out in the acute stage in two of eight patients and revealed detrusor hyperreflexia in 
Table 2 Clinical, urodynamic, and MRI findings in patients with acute transverse myelitis at followup

\begin{tabular}{|c|c|c|c|c|c|c|c|c|}
\hline \multirow[b]{2}{*}{ Case No } & \multicolumn{2}{|c|}{ Bladder symptoms } & \multicolumn{2}{|l|}{ Tone } & \multicolumn{2}{|c|}{ Power } & \multicolumn{2}{|c|}{ Urodynamics } \\
\hline & $6 \mathrm{~m}$ & 1 year & $6 \mathrm{~m}$ & 1 year & $6 \mathrm{~m}$ & 1 year & $6 \mathrm{~m}$ & 1 year \\
\hline 1 & $R$ & $R$ & $\uparrow$ & $\uparrow$ & 1 & 1 & DA & - \\
\hline 2 & $F, S$ & $\mathrm{~F}, \mathrm{~S}, \mathrm{H}, \mathrm{U}$ & $N$ & $\uparrow$ & 4 & 5 & DA & - \\
\hline 3 & $F, U$ & - & $\uparrow$ & - & 4 & & $\mathrm{DH}+\mathrm{DSD}$ & - \\
\hline 4 & $\mathrm{~F}, \mathrm{U}$ & $\mathrm{F}, \mathrm{U}$ & $\uparrow$ & $\uparrow$ & 4 & 5 & $\mathrm{DH}+\mathrm{DSD}$ & - \\
\hline 5 & $\mathrm{~F}, \mathrm{UI}, \mathrm{U}$ & $\mathrm{F}, \mathrm{U}$ & $\uparrow$ & $\uparrow$ & 4 & 4 & $\mathrm{DH}$ & - \\
\hline 6 & $F, U$ & $F, U$ & $\uparrow$ & $\uparrow$ & 4 & 4 & - & $\mathrm{DH}$ \\
\hline 7 & $N$ & - & $\mathrm{N}$ & - & 5 & & - & - \\
\hline 8 & $\mathrm{R}$ & - & $\downarrow$ & - & 0 & & - & - \\
\hline 9 & $\mathrm{R}$ & - & $\uparrow$ & - & 3 & & - & - \\
\hline 10 & $\mathrm{~F}, \mathrm{H}, \mathrm{S}$ & - & $\uparrow$ & - & 5 & & - & - \\
\hline 11 & $\mathrm{R}$ & - & $\downarrow$ & - & 3 & & - & - \\
\hline 12 & $N$ & - & $N$ & - & 5 & & - & - \\
\hline 13 & $\mathrm{~F}, \mathrm{~S}, \mathrm{U}$ & - & $\uparrow$ & - & 4 & & - & - \\
\hline 14 & $\mathrm{~F}, \mathrm{~S}$ & - & $\uparrow$ & - & 4 & & - & - \\
\hline 15 & $\mathrm{R}$ & - & $\downarrow$ & - & 0 & & - & - \\
\hline 16 & $F, U, U I$ & $F, U, U I$ & $\uparrow$ & $\uparrow$ & 4 & 4 & $\mathrm{DH}+\mathrm{DSD}$ & $\mathrm{DH}+\mathrm{DSD}$ \\
\hline 17 & $\mathrm{R}$ & $\mathrm{R}$ & $\downarrow$ & $\downarrow$ & 0 & 0 & - & $\mathrm{DA}$ \\
\hline 18 & $\mathrm{~F}, \mathrm{H}, \mathrm{S}$ & $\mathrm{F}, \mathrm{S}, \mathrm{H}$ & $N$ & $\uparrow$ & 3 & 5 & - & $\mathrm{DH}$ \\
\hline
\end{tabular}

DA, detrusor areflexia or hyporeflexia; DH, detrusor hyperreflexia; DSD; detrusor sphincter dyssynergia; $F$, frequency; $H$, hesitancy; $N$, normal; $R$, retention; S, straining; $U$, urgency; UI, urge incontinence.

one and detrusor external sphincter dyssynergia in the other. One of these patients did not have any sensory or motor abnormalities. The absence of any sensory or motor findings in these patients raises doubts about the diagnosis of acute transverse myelitis. In the third study, ${ }^{5}$ Sakakibara et al evaluated bladder function in 10 patients with acute transverse myelitis, of whom seven had retention of urine and three had difficulty in voiding. Five patients underwent urodynamic studies in the acute stage and were shown to have detrusor areflexia with sphincter hyperreflexia. Our patients fulfilled stringent inclusion criteria for acute transverse myelitis, were evaluated within one month of disease onset, and in some cases were followed up sequentially. However, we noted detrusor sphincter dyssynergia in only three patients and detrusor hyperreflexia in two in the acute stage.

The finding of an areflexic or hyporeflexic bladder in our patients was correlated with lower limb hypotonia and areflexia. This could reflect the proximity of the reticulospinal pathway to the corticospinal pathway, the former being responsible for supraspinal bladder control. In acute transverse myelitis, the hyperintense lesions on MRI are mostly present in the central two thirds of the spinal cord, which may result in simultaneous involvement of both these pathways. In two patients with lower limb hypotonia there was detrusor sphincter dyssynergia, and in one patient with grade IV lower limb power and spasticity there was an areflexic bladder.

In the acute stage of acute transverse myelitis there may be a varying period of spinal shock which can persist up to six weeks. ${ }^{14}$ This gradually gives way to spasticity, depending on the interplay between anterior horn cell excitability and supraspinal influences. Resolution of spinal shock and its replacement by limb spasticity may parallel similar changes in bladder innervation. This could explain the discordance between muscle tone and the pattern of bladder function in the three patients mentioned above.

The bladder dysfunction in our patients did not correlate with the extent of MRI changes, although an areflexic or hyporeflexic bladder was commoner with lumbosacral spinal segment involvement. This may reflect involvement of the lumbosacral segments of spinal cord which are crucial for bladder control. Sympathetic function is controlled by the dorsolumbar segments (D12-Ll,2) and parasympathetic function by the sacral segments, along with somatic control of the sphincters. All the five patients with lumbosacral signal changes on MRI had hyporeflexic or areflexic bladders. On follow up at six months in two patients with lumbosacral involvement, the bladder remained hypocontractile. However, among eight patients with cervicodorsal involvement, a hypocontractile bladder was present in the acute stage in only four; at the six months follow up, there was detrusor hyperreflexia in one and detrusor hyperreflexia with sphincter dyssynergia in three.

One patient with persistent detrusor areflexia had normal MRI. This patient, however, had fibrillations on lower limb muscle EMG. Two other patients with detrusor areflexia also had fibrillations in the lower limb muscles. In these patients the pathology may have involved the Onuf nucleus as well. In a necropsy study, inflammation and demyelination of the spinal cord extended from the cervical to the lumbosacral region. ${ }^{15}$ The patient described had sensory loss up to D3 level. We have reported anterior horn cell involvement in acute transverse myelitis, on the basis of EMG findings, and we found this to be a poor predictor of outcome. ${ }^{16}$

Somatosensory and motor evoked potential changes did not correlate with the pattern of bladder dysfunction in our study. This is, however, not surprising because sensory motor pathways are distinct from the autonomic fibres controlling the sacral micturition centre. Abnormalities of evoked potentials only reflect the extent and severity of the respective pathways in the spinal cord in acute transverse myelitis. In multiple sclerosis, bladder symptoms have been reported to be associated with the presence of pyramidal signs in the lower limbs. Detrusor hyperreflexia is the commonest pattern of bladder dysfunction in multiple sclerosis, occurring in 52-78\% of patients. ${ }^{17-19}$ Acute transverse myelitis may be the first presentation of multiple sclerosis. In our study, however, $66 \%$ of patients had detrusor areflexia or hyporeflexia. This may reflect the associated involvement of grey matter along with the long tracts in acute transverse myelitis, whereas multiple sclerosis is a disease of white matter. Acute transverse myelitis in tropical countries is mostly of parainfectious origin, and this is supported by the presence of fibrillations in seven of our patients. Detailed virological studies could not be undertaken, however.

The presence of bladder dysfunction and the pattern of urodynamic change in the acute stage did not correlate with the six months outcome of our patients as reflected in the Barthel index score. In our study, a varying degree of clinical improvement was noted in seven patients, and 11 patients made a full recovery. Of those, nine had urinary symptoms in the form of frequency, urgency, and hesitancy. In seven patients who made a full recovery, urodynamic studies showed a hypocontractile 
bladder in one and detrusor hyperreflexia in six; three of the latter had detrusor sphincter dyssynergia. All patients with detrusor hyperreflexia had a detrusor leak point pressure exceeding $40 \mathrm{~cm} \mathrm{H}_{2} \mathrm{O}$, which has been shown to be associated with a significantly increased risk of renal damage. ${ }^{18}$ Detrusor sphincter dyssynergia also predisposes to urological complications. ${ }^{2}$ The lack of clinical and urodynamic correlation was emphasised in an earlier study as well, in which detrusor hyperreflexia persisted after 13 years in spite of full clinical recovery. ${ }^{4}$

Clean intermittent self catheterisation could be maintained in only a small number of patients, despite our best efforts. This may reflect a lack of motivation or the sociocultural background.

Our results highlight the importance of urodynamic studies in patients with acute transverse myelitis, especially in those with detrusor sphincter dyssynergia or hypertonic bladder, so that appropriate measures can be taken.

\section{ACKNOWLEDGEMENTS}

We gratefully acknowledge the technical assistance of Rakesh Kumar Nigam and S P Singh.

\section{Authors' affiliations}

J Kalita, S Shah, U K Misra, Department of Neurology, Sanjay Gandhi PGIMS, Lucknow, India

R Kapoor, Department of Urology, Sanjay Gandhi PGIMS

\section{REFERENCES}

1 Kaplan SA, Chancellor MB, Blaivas JG. Bladder and sphincter behaviour in patients with spinal cord lesions. J Urol 1991;46:113-17.

2 Blaivas JG, Barbalias GA. Detrusor external sphincter dyssynergia in men with multiple sclerosis: an ominous urologic condition. J Urol $1984 ; 131: 91-4$
3 Misra UK, Kalita J, Kapoor R. Postural hypotension in a patient with cervical myelopathy due to craniovertebral anomaly. Clin Autonom Res 1997;7:223-6.

4 Berger Y, Blaivas JG, Oliver L. Urinary dysfunction in transverse myelitis J Urol 1990;144:103-6.

5 Sakakibara R, Hittori T, Yasuda K, et al. Micturition disturbance in acute transverse myelitis. Spinal Cord 1996;34:481-5.

6 Jeffery DR, Mandler RN, Davis L. Transverse myelitis - retrospective analysis of 33 cases with differentiation of cases associated with multiple sclerosis and parainfectious events. Arch Neurol 1993;50:532-5.

7 Penn RD, Savoy SM, Corcos D, et al. Intrathecal baclofen for severe spinal spasticity. N Engl J Med 1989;320:1517-21.

8 Misra UK, Kalita J, Kumar S. A clinical, MRI and neurophysiological study of acute transverse myelitis. J Neurol Sci 1996;138:150-6.

9 Wyndacle JJ. The normal pattern of perception of bladder filling during cystometry studied in 38 young healthy volunteers. J Urol 1998; 160:479-81.

10 Barrett DM, Wein AJ. Voiding dysfunction: diagnosis, classification and management. In: Gillenwater JY, Grayhack JT, Howards SS, et al, eds. Adult and pediatric urology, vol I. Chicago: Year Book Medical Publishers, 1987:863-962.

11 Abrams P, Blaivas JG, Stanton SL, et al. Standardisation of terminology of lower urinary tract function. Neurourol Urodynam 1988;7:403-27.

12 Mahony FE, Barthel DW. Functional evaluation: the Barthel index. Md Med J 1986;14:61-5.

13 Pradhan S, Gupta RK, Kapoor R, et al. Parainfectious conus myelitis. J Neurol Sci 1998;161:156-62.

14 Guttmann L. Spinal shock. In: Vinken PJ, Bruyn GW, eds. Handbook of clinical neurology, vol 26. Injuries of the spine and spinal cord, part II. Amsterdam: North Holland, 1976:243-62.

15 Hoffman HL. Acute myelopathy. Brain 1955;78:377-93.

16 Misra UK, Kalita J. Can electromyography predict the prognosis of transverse myelitis? Acta Neurol Scand 1998;245:741-4.

17 Anderson JT, Bradley WE. Abnormalities of detrusor and sphincter function in multiple sclerosis. Br J Urol 1976;48:193-8.

18 McGuire EJ, Savastano JA. Urodynamic findings and long term outcome management of patients with multiple sclerosis induced lower urinary tract dysfunction. J Urol 1984;132:713-15

19 Betts CD, D'Mellow MT, Fowler CJ. Urinary symptoms and the neurological features of bladder dysfunction in multiple sclerosis. J Neurol Neurosurg Psychiatry 1993;56:245-50. 